\title{
A cost and benefit analysis of future end-of- life vehicle glazing recycling in France: a systematic approach
}

First/contact author: Romain Farel

contact:

tel : +33141131818

fax: +33 141131272

email: romain.farel@ecp.fr

Coauthors: Bernard Yannou, Asma Ghaffari, Yann Leroy

Affiliation for all the four:

Laboratoire Genie Industriel, Ecole Centrale Paris, Grande Voie des Vignes, Chatenay-Malabry, France

For citation:

R. Farel, B. Yannou, A. Ghaffari et al., "A cost and benefit analysis of future end-of-life vehicle glazing recycling in France: a system dynamics approach," Resources, Conservation and Recycling, vol. xx, 2013

DOI: 10.1016/j.resconrec.2013.02.013 


\section{Introduction}

Each year, the lives of 8 million vehicles in Europe come to an end, of which France has a share of 1.8 million (ADEME 2008). Glass represents $2.9 \%$ of the weight of the typical European End of Life Vehicle (ELV) (ADEME 2007). It is a component of windshields, side windows and back windows. This integrated glass is generally called car glazing. Given that France alone produces $41 \mathrm{~kg}$ of glazing per ELV, about 70,000 tons of glazing is produced per year, not to mention the 20,000 tons of replacement glass. This is a considerable volume. The situation is exacerbated by the fact that $90-$ $95 \%$ of this significant quantity of glass is disposed in landfills today, where it is mixed with other residues from shredding operations.

The publication of the European directive number 2000/53/CE announced an important challenge to the automotive industry. This, albeit ambitious, target is imposed by the directive's attempts to reuse or recover at least $95 \%$ of the ELV weight by $2015,90 \%$ of which is recycling (EU-Directive 2000). The recycling of ELV materials has been promoted for several years now by automotive industries across all EU countries. However, this effort in the majority of countries, including France, has been limited to materials such as steel and aluminum, and not minor wastes such as glazing (Gerrard and Kandlikar 2007). The new recycling target (95\%) calls for considering glazing recycling. Clearly, a dramatic increase in the recovery of plastic, rubber, glass and other non-metallic materials will need to take place. The removal of glazing is nonetheless given explicit mention in the minimum operations obligations when ELV comes to dismantling.

Sending ELV glazing to landfill does not cause serious environmental problems. It is mixed with other residues and polluted with organic material. The treatment and recycling of glass does however become difficult, expensive, and thus unfeasible. Hence, it is possible to dismantle the glass from ELV, collect and transport the glass to treatment units, purify the glass and obtain clean and reusable glass raw material called cullet. Cullet can be reused in making glass products, and is a substitute in other raw material markets. The glass production industry uses cullet to two advantages: it is relatively less expensive than raw material (Silica) and consumes less electrical energy in the furnaces for melting (Remade-Scotland 2003). Besides the aforementioned economic advantages, using cullet saves tons of natural resources from being exploited, transported, treated and consumed to make glass products. Thus, the reuse of cullet positively contributes in several ways to the environment.

Creating an ELV glazing value chain helps to achieve the EC directive, create value in glass recycling and reuse, and contribute to the environment in aspects previously detailed. The ELV glazing value chain is defined as a set of activities needed to transform the ELV glazing into secondary raw material, for glass or other product manufacturing. However, a major difficulty is that recycling and reusing is not the concern of a single firm, but of a pool of stakeholders cooperating along a value chain. The main stakeholders are the car manufacturer, the dismantling unit, the collection, storage and redistribution company, and the glass treatment unit. Details about the operational activities of these stakeholders are provided in section 5.

The ultimate objective of this research is to create an ELV glazing recycling value chain at a national level. To do this from scratch, two conditions must be met. The first is to build an industrial consortium on a national scale gathering the representative stakeholders of the future recycling chain. It would be advisable to incite industrial companies to invest in new collection organizations, warehouses, and purification technologies. The second condition is to be able to prove that such an 
industrial investment is profitable for the whole chain including its economic stakeholders, which is the objective of this paper.

This paper is organized as follows: section two reviews the CBA approaches in general and in environmental studies and applications. Section three defines the recycling process and a dynamic model of the system and the relationships between variables. In section four the future trends for the recycling network are explained. Section five presents the field research and data collection at national level and with industrial partners. Section six uses the data to simulate different dynamics for key variables, and produce best, expected and worst case dynamics for endogenous and exogenous variables. In section seven, the result of network cost and benefits in nine future scenarios is presented and the advantages are discussed. In the final portion of the paper, conclusions are drawn on a future national glazing recycling network and provide recommendations for a further understanding on the subject.

\section{Cost-Benefit Analysis of a recycling scheme}

Cost-benefit analysis (CBA) is the primary tool that economists employ to determine whether a particular policy, or policy proposal, promotes economic efficiency (Kotchen 2011). In this vein, both positive and negative impacts of an action are converted into a common cash balance, thus cost and benefit is subject to a simple test of whether the benefits exceed the costs.

Although CBA was originally conceived to apply to projects undertaken in the public sector, it has been applied more and more to private sector project proposals (Boardman, Greenberg et al. 2001), or large-scale private sector projects subject to public participation and investment (Campbell and Brown 2005). The reason is that CBA is straightforward and easy to understand, and to share with project partners and stakeholders. Since the early 2000s, CBA has been adapted and widely practiced in the field of environmental policy (Pearce, Atkinson et al. 2006), and driven towards long-term sustainability through eco-restructuring (Joe 2008).

In solving recycling chain problems, CBA has shown to be beneficial. For example Leu (1998) used CBA to perform cost analysis leading to improving the financial health of a resource material recycling center. $C B A$ is shown to be reliable for generating decision elements for decision makers, as shown Yuan et al. in deploying CBA for management of a waste chain (Yuan, Shen et al. 2011). The use of CBA is not limited to an existing system, and can be deployed for analysis of futur scenarios, for example to put forward the result of different economic instrument scenarios (Duran, Lenihan et al. 2006).

The benefits of CBA at preliminary evaluation of multi-stakeholder projects according to Campbell (2005) are; (i) the ease with which a given project can be evaluated from alternative decision-making perspectives, which involves considering the distribution of costs and benefits among the affected stakeholders; and (ii) the provision of an in-built check on internal consistency in deriving the project's net benefit streams and assigning costs and benefits to the relevant stakeholders. It is obvious that the costs and benefits for stakeholders are not equally distributed.

In the present paper, the CBA of recycling glazing is considered within the general recycling scheme of ELV materials. ELV recycling has been subject to several research studies in the Economic and 
Environmental Sciences. In the ELV recycling literature, studies go from dismantling technologies (Suzuki, Sato et al. 2001) and separation techniques (Malcolm Richard, Mario et al. 2011), to the critical review on policies and strategies (Gerrard and Kandlikar 2007; Zhao and Chen 2011) and economic models (Bellmann and Khare 2000; Duval and MacLean 2007).

However, there is little research conducted on glass recycling chains. Pieters (1986) and Robert (1990) pointed out the importance of source separation in glass recycling from municipal wastes. Sardeshpande (2007) proposed a model to optimize the energy consumption of glass furnaces, and reported on the effect of cullet use. Butler (2005) investigated the environmental gains to be made from substituting glass-container feedstock for virgin raw material in the production of glass containers and base aggregates. Shi promoted the use of waste glass in the production of cement and concrete (Shi and Zheng 2007), and Kourti reported on advantages of using glass for manufacturing of the sintered lightweight aggregate product, due to a lower firing temperature coupled with an improvement in physical and mechanical properties of the product (Kourti and Cheeseman 2010).

For an ELV glazing recycling scheme, the total cost is the sum of all operational costs. This includes glazing dismantling, collection and transport, and treatment steps. The direct benefit of this recycling scheme is saving costs of landfill, generating revenue from selling cullet for reuse as raw or substitution material in glass production as well as potentially saving the cost of penalty in instances of not achieving the EU directive limit of $95 \%$. ELV glazing recycling cost and benefits belong, undeniably, to different stakeholders. A CBA only makes sense if the recycling scheme is considered as a whole, and is to be managed with respect to all stakeholders to redistribute income.

Stakeholders, however, are likely to produce winners and losers, and CBA requires only that the gains to the winners exceed the losses to the losers (Kotchen 2011). Campbell (2005) formulated three questions a decision maker needs to answer: 1) Is the proposed project efficient from a private market perspective? 2) Is the project profitable from the perspective of the entities undertaking the investment? 3) Does the project contribute to economic efficiency by improving the global allocation of scarce resources?

This paper positions the ELV glazing recycling network within the following framework of questions for stakeholders: CBA is a prominent tool to provide adequate information of operational costs and market prices for stakeholders' investigations of the techno-economic efficiency of the ELV glazing recycling network. In response to the latter question, a system dynamics model is developed to simulate the changes in key variable values in the future, and estimate the effect of these changes on the CBA of the network. Assuming that economic efficiency of a future recycling network is economically viable, this paper shows the CBA of ELV glazing recycling in the present situation and under estimated future conditions, associated with material flow. Therefore, it is possible to use an indicator for saved ELV glazing from landfill of economic efficiency the network.

\section{Methodology}

\section{1 recycling network value chain}

Within the limits of this study, the set of all operational steps of the ELV glazing recycling network on is presented in Figure 1. Each activity is a process of material transformation implying the quality 
change. This change indicates an economic value (cost or benefit, $V_{i}$ ) and an environmental value expressed as the carbon footprint $\left(\mathrm{CO}_{2}\right.$ saving or emission, $\left.\mathrm{E}_{\mathrm{i}}\right)$.

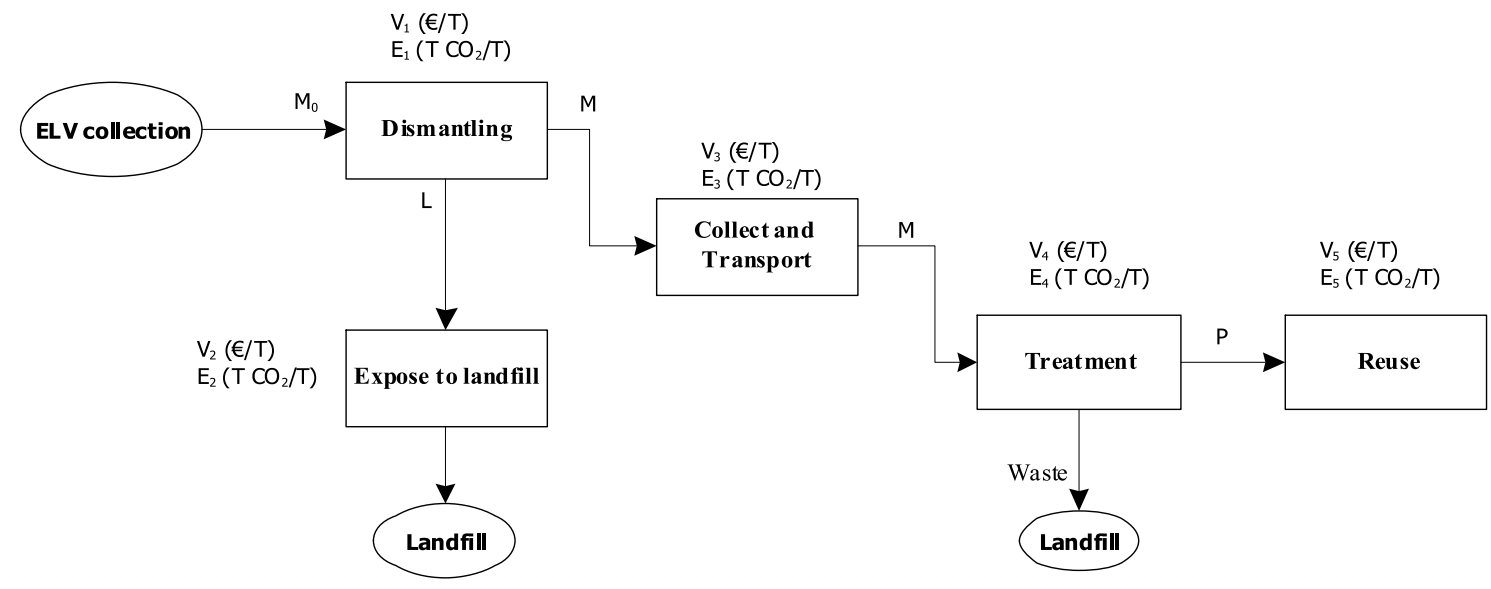

Figure 1. ELV glazing recycling network at national level

In order to implement a CBA, is it necessary to collect detailed information of activities, parameterize costs, incomes and environmental contribution in accordance with the material flow unit. Although a great deal of information at the macroscopic level can be extracted from official public reports such as the French Environment and Energy Management Agency (ADEME) and European Commission Environment, information on particular operations in glazing recycling is yet to be obtained from field research. To compensate for this lack of information, a series of interviews were held, with at least one representing stakeholder for each activity within the recycling network. Parameters and constraints have also been obtained through interviews with industrial and recycling professional partners on a national level. Table 1 summarizes both the economic and environmental values of the ELV glazing recycling network activities. This information has been obtained mainly from national public reports and through interviewing adequate business owners, mentioned in the last row. The details of CBA and environmental impact are presented in section 4.

Table 1. Economic and environmental impact elements for ELV glazing recycling network

\begin{tabular}{|c|c|c|c|c|c|}
\hline & Dismantling & $\begin{array}{l}\text { Collect and } \\
\text { landfill }\end{array}$ & Transport & Treatment & Recycle \\
\hline $\begin{array}{c}\text { ELV glazing } \\
\text { network } \\
\text { activity } \\
\end{array}$ & $\begin{array}{c}\text { Dismantling the } \\
\text { glazing } \\
\text { Storage }\end{array}$ & $\begin{array}{l}\text { Collect } \\
\text { glazing, } \\
\text { storage }\end{array}$ & $\begin{array}{c}\text { Transport } \\
\text { glazing to glass } \\
\text { treatment }\end{array}$ & $\begin{array}{l}\text { Treatment of } \\
\text { ELV glass }\end{array}$ & Re-melt cullet \\
\hline $\begin{array}{c}\text { Cost } \\
\text { estimation }\end{array}$ & $\begin{array}{c}40-50 € / \mathrm{T} \\
\text { removed } \\
\text { glazing }\end{array}$ & $\begin{array}{l}108,4 € / T \\
\text { landfill cost }\end{array}$ & $\begin{array}{c}\text { 60-85 /T } \\
\text { glazing }\end{array}$ & $\begin{array}{l}20-30 / T \text { cullet } \\
\text { (buy+process) }\end{array}$ & \\
\hline $\begin{array}{c}\text { Income } \\
\text { estimation }\end{array}$ & $10-15 € / \mathrm{T}$ sale & $\begin{array}{c}80 € / T \\
\text { Saving costs } \\
\text { in landfill } \\
\text { cost }\end{array}$ & & $\begin{array}{c}40-50 € / T \text { Sale } \\
\text { cullet }\end{array}$ & $\begin{array}{l}2-5 € / t \text { cullet } \\
\text { price difference } \\
\text { (cullet - raw } \\
\text { material), }\end{array}$ \\
\hline $\begin{array}{c}\text { Emission } \\
\text { TCO2/T }\end{array}$ & Negligible & Negligible & 0.04 /T glazing & $\begin{array}{c}0.0019 / \mathrm{T} \\
\text { cullet }\end{array}$ & $-0.23 / \mathrm{T}$ glass \\
\hline Barriers & $\begin{array}{c}\text { Extra cost, no } \\
\text { buyer }\end{array}$ & - & Cost, no buyer & $\begin{array}{c}\text { No } \\
\text { considerable } \\
\text { amount }\end{array}$ & Quality issues \\
\hline $\begin{array}{l}\text { Economic } \\
\text { motivation }\end{array}$ & $\begin{array}{l}\text { Granting sale, } \\
\text { subside }\end{array}$ & $\begin{array}{c}\text { Saving } \\
\text { landfill costs, } \\
\text { saving landfill } \\
\end{array}$ & $\begin{array}{c}\text { Granting sale, } \\
\text { extension and } \\
\text { mutual }\end{array}$ & $\begin{array}{c}\text { Improving } \\
\text { capacity (5- } \\
10 \%)\end{array}$ & $\begin{array}{l}\text { Energy saving in } \\
\text { furnace, less } \\
\text { CO2 emission } \\
\end{array}$ \\
\hline
\end{tabular}




\begin{tabular}{c|cc|}
\hline capacity & $\begin{array}{c}\text { development of } \\
\text { the network }\end{array}$ \\
\hline
\end{tabular}

\subsection{System dynamics model}

The economic balance of cost and benefit of each operational activity are subject to change. This arises from the change in the values of parameters, which determine the costs and profits (or any given cost or profit). The dynamics of these changes can be explained using System Dynamics modeling (Sterman 2000). System dynamics simulation is a renowned approach to simulate the effect of future changes, which has been recently used in the area of recycling (Yuan, Shen et al. 2011; Zhao, Ren et al. 2011). It shows the cause and effect diagram of the glazing recycling network. There are two main mechanisms here, which have direct influence on the CBA of the network. The first mechanism concerns itself with the benefits, in the form of sales and savings, of glazing recycling. The second mechanism deals with the glazing recycling cost, composed of the operational and logistic costs of the network, in addition to the potential penalty. The CBA is the sum of benefits minus the sum of cost. There are, however, a number of interconnections between two mechanisms. For example, the increase in benefits encourages more stakeholders to join the recycling network. Thus, the network coverage increases and this leads to a decrease in logistic costs, which then ripples into a decrease in total cost of the recycling network. The latter, influences motivation for joining the network, and results in a positive loop.

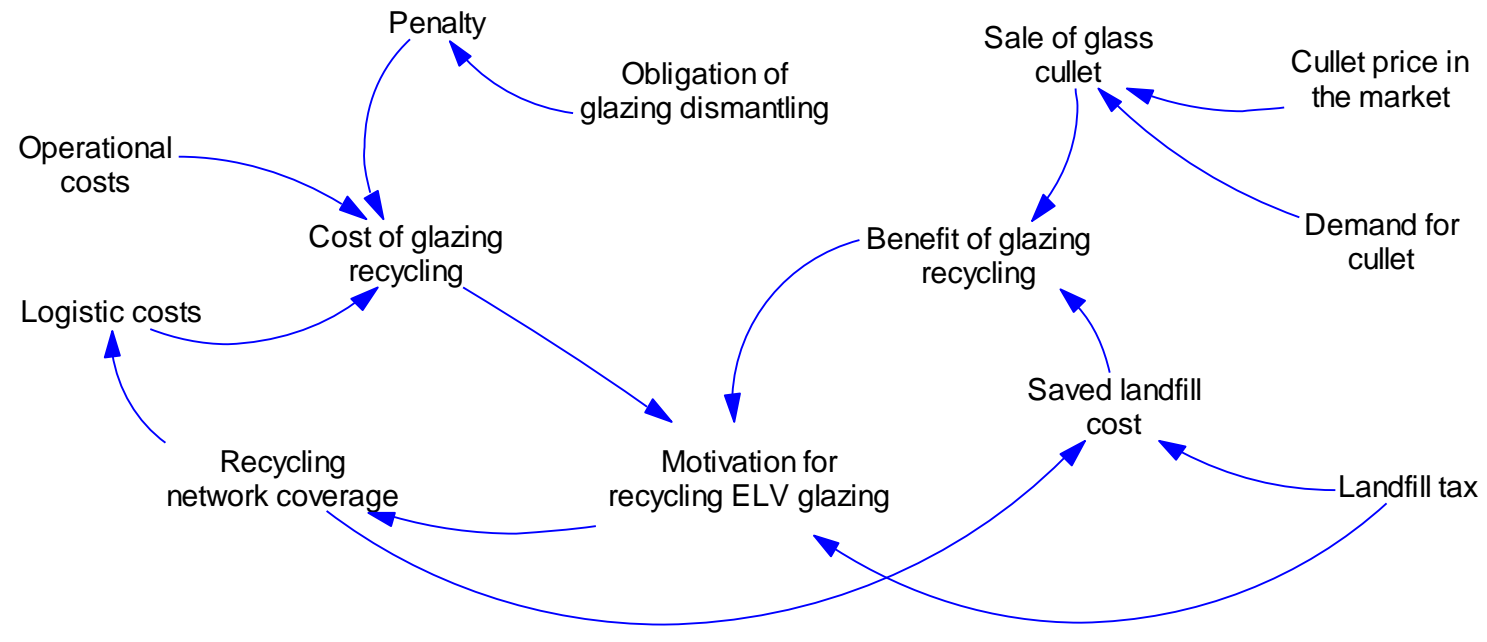

Figure 2. System dynamics model of ELV glazing recycling network

Creating a national recycling network and increasing the coverage rate is an endogenous change of the model. This change positively influences the saved cost of landfill, and decreases the logistics and the total cost of establishing this network. This aside, there are several time-varying elements from different exogenous sources that influence the behavior of the system.

The first category of exogenous variables is the raw-material market evolution: change in cullet price and cullet demand. The dynamic of this change is explained in the following section. The second category is the politico-environmental decisions, which result in change in landfill tax, and in applying 
a penalty if the minimum recycling rate is not reached. The EU directive penalty on ELV reuse and recovery minimum rate of $95 \%$ is one example of this category. The increase in landfill tax increases the motivation to recycle. The benefit of saved landfill cost can be visualized in the following scenario: initially, the glazing is not dismantled from the ELV shell, and goes through the shredding process, ends up in the Automotive Shredder Residue (ASR). The average weight of ASR after metal and plastic separation is $97,1 \mathrm{~kg}$ (ADEME 2006) to be taken to landfill, of which $40 \mathrm{~kg}$ is glazing, approximately $41 \%$ weight. Therefore, removing glazing at the level of the dismantling unit results in $41 \%$ cost saving in landfill, without mentioning the transportation and operation cost of taking to landfill. Unexpectedly, in the present situation, the economical balance of shredding and landfill does not create motivation to change the trade off in favor of glazing recycling. However, the increase in landfill cost bears significant results for difference in cost when it comes to the shredding.

Along similar lines, if a penalty is applied in the instance of not reaching the minimum rate, and given the hypothesis that reaching the minimum rate is not possible without recycling the glazing, the car manufacturer tries first to negotiate with dismantling partners in favor of glazing removal from the ELV shell.

\section{Future trends and scenarios for ELV glazing recycling}

The evolution of system variables would have influence over the Future ELV glazing recycling network dynamics and consequently its cost and benefit. In a top-down approach, two trends can be imagined for the future network: first, the generation of network revenue, and second the decrease the operational costs. These two trends are explained as sub-systems in this section. Analysis of the cause and effect relationship between network variables reveals the importance of political decisions from outside of the system, and strategic decisions from within on the dynamic. As a result, a third trend emerges, identifying the dynamics of internal and external motivation and decision variables on the network functions.

Each trend develops a different kind of logic for the CBA of the network: In the first trend, redistribution of the revenue is an economic motivation: if the revenue of the recycling network goes beyond break-point, establishing a consortium of stakeholders to assure the collection and production of cullet is economically viable for all stakeholders involved. In the second trend, creating a consortium to establish a recycling network helps to decrease the costs. In the third trend, external obligations may contribute to both the potential increase in revenue and the increase in the cost of not recycling. In both situations creating a consortium of stakeholders and establishing a glazing recycling network would prove beneficial for all.

The sub-systems of each trend isbased on field work and interviews with business experts. The relationship between those variables creates a dynamic for the trend, which will be detailed in the following section. Certain dynamics are identified in each trend to simulate the CBA of the recycling network. A simulation and obtain numerical results for future glazing recycling, over a 50-year period and an estimated value curve of the focal variable in each trend, is presented in section 5.

\subsection{Generation of network revenue}

The ELV glazing recycling network revenue is earned from producing glass cullet and selling it on the market. Apart from being used as raw material in glass production, glass cullet is used extensively to produce isolation products such as glass wool. It can also be used as substitution material in several 
applications (Table 2). Like any other product, the demand and price of cullet strike an equilibrium. However, exogenous variables can break and transform the equilibrium into a different state. Figure 3 demonstrates the cause and effect diagram of variables influencing the network revenue through influencing the demand and the price of cullet in the market. The causal relationship is explained as follows.

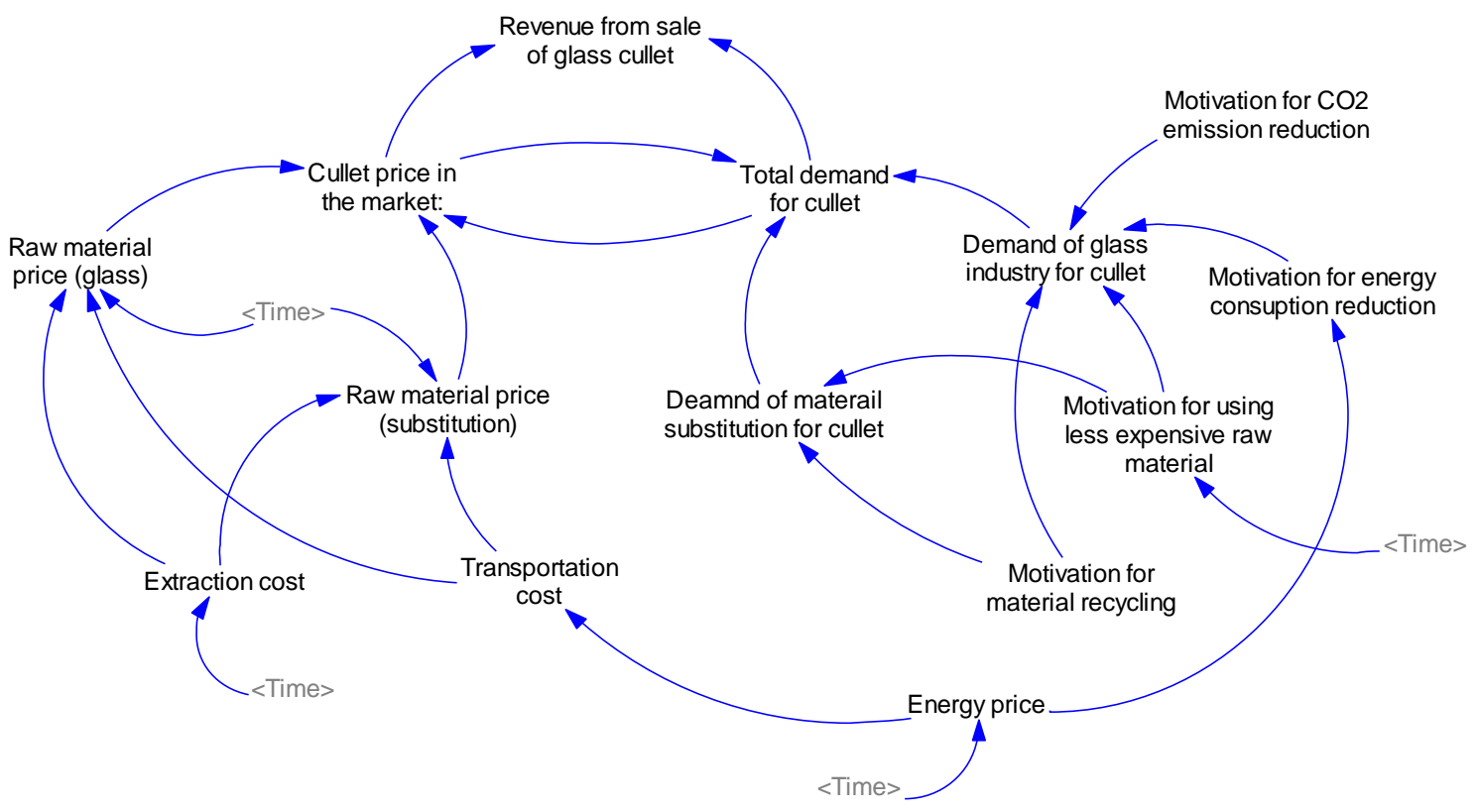

Figure 3. Dynamics of revenue generation for ELV glazing recycling

The use of cullet is of substantial importance for the glass Industry. Re-melting glass to form new glass products has wide-ranging environmental benefits. It contributes to reducing energy consumption, i.e. less energy is required to re-melt glass than to melt the equivalent amount of raw materials. It reduces $\mathrm{CO} 2$ emissions as less raw materials required and especially carbonates which release carbon dioxide and it saves valuable natural resources thus minimizing quarrying activity and reducing the volume of waste going to landfill. For each $10 \%$ increase in cullet usage there is an energy savings of $2-3 \%$ when it comes to the melting process and each ton of cullet used saves 230 $\mathrm{kg}$ of $\mathrm{CO}_{2}$ emitted (Glass 2009).

The need of cullet for the glass industry has steadily been increasing in recent years (Wrap, 2008). About $90 \%$ of the world's flat glass is produced as float glass. This is mainly to supply the building industry, which accounts for $75 \%$ to $85 \%$ of the output. This is also for the car manufacturing industry, which accounts for 15 to $25 \%$ of the output. The majority of rolled glass is produced as patterned glass or wired glass. The current share of post-consumer cullet applied in flat glass manufacturing is reported to be between 5 and $10 \%$ for the reuse of post-consumer glass in the flat glass industry, a low which is to be pushed up (Glass 2009). However, considering the EU-27 as the world's largest glass market, and the total production in 2008 was 36.33 million tons, 10.26 million tons of flat glass (NACEGroup 2009). The demand for good quality cullet is both significant and ever increasing.

If by any dysfunction of activities for providing good cullet, the quality fails to satisfy the flat glass production requirements. Other possible means affect the cullet for glass production in container 
glass, or fiberglass manufacturing industry. Cullet can also be used in several substitutions, detailed in Table 2, extracted from (Reindl 2003).

Table 2. Non-glass application and use examples for cullet

\begin{tabular}{|c|l|}
\hline Application & \multicolumn{1}{|c|}{ Examples } \\
\hline Building Material & $\begin{array}{l}\text { Aggregate, Counter Tops, Molding } \\
\text { Doors, Glass Brick, Glass Tile, Masonry Coating, Mosaic Glass, Plastic-composite "Lumber", } \\
\text { Roof Shingles, Roof Tile, Skylights, Stone, Terrazzo, Wall Panels }\end{array}$ \\
\hline $\begin{array}{c}\text { Concrete } \\
\text { Applications }\end{array}$ & Concrete Additive, Concrete Aggregate \\
\hline $\begin{array}{c}\text { Construction } \\
\text { Aggregates }\end{array}$ & $\begin{array}{l}\text { Aggregate Base Course, Drainage Aggregate, Highway Fill, Landfill Cover, Landfill Gas } \\
\text { Venting Systems, Landfill Leachate, System Filter, Landfill Liner Cover, Utility Trench Fill }\end{array}$ \\
\hline $\begin{array}{c}\text { Industrial } \\
\text { Mineral Uses }\end{array}$ & Sandblasting \\
\hline $\begin{array}{c}\text { Insulation } \\
\text { Applications }\end{array}$ & Fiberglass Insulation, Foamglass Insulation \\
\hline $\begin{array}{c}\text { Paving } \\
\text { Applications }\end{array}$ & $\begin{array}{l}\text { Aggregate, Asphalt (Glasphalt), Concrete, Paving Bricks, Road Construction, Roadbed } \\
\text { Aggregate }\end{array}$ \\
\hline $\begin{array}{c}\text { Remelt } \\
\text { Applications }\end{array}$ & \begin{tabular}{l} 
Art Glass \\
\hline $\begin{array}{c}\text { Miscellaneous } \\
\text { Applications }\end{array}$
\end{tabular} \\
$\begin{array}{c}\text { Abrasive, Agricultural Fertilizer, Beach Sand, Ceramic Glazes, Designer Clothes, Filler for } \\
\text { Plastics, Filter (General), Floor Grit, Flowable Fill, Glass Beads, Glass Foam, Glass Polymer } \\
\text { Hydroponic Growth Medium, Jewelry, Landscaping, Stonewash Abrasive, Tableware, } \\
\text { Traction, Waste Water Filter, Water Filter }\end{array}$ \\
\hline
\end{tabular}

The reuse of cullet for non-container usage implies less quality restriction. However, the marginal nature of the market and the lower given price are not in favor of making value through a recycling network. The substitution usage should be privileged if there is no possibility for the network against the landfill disposition of glass, such as small and local network of a low volume.

The demand for cullet would increase as a result of several incentives: motivation for energy consumption reduction, motivation for $\mathrm{CO} 2$ emission reduction, motivation for raw material cost reduction, and motivation for material recycling (as opposed to landfill). Those motivations are being weakened or strengthened, due to endogenous elements, as shown in Figure 3. The general market time-varying variables such as energy price and fuel price in particular, significantly increase the motivation of energy consumption reduction in furnace. The fuel price increase implies a general increase raw material transportation price. Both mechanisms contribute towards an increase in cullet demand and cullet price in the market.

We instruct the first set of scenarios to simulate the glazing recycling network CBA by varying the cullet price amount. Three scenarios are chosen to demonstrate worst, average and best situations for cullet price, presented in section 5 .

\subsection{Decrease the ELV recycling costs}

Operation and transportation of cost cullet production are the main opposing factors to the glazing recycling network. The total cost of glazing recycling is broken down to the following costs, shown in figure 4: dismantling, collection, storage, transportation, and treatment. Each of these costs is a function of several parameters, containing network-dependent variables. The latest are the variables, which are changing as a result of establishing a large scale glazing recycling network. 
The most important costs are collection and transportation, which are in general, considerably influenced by the effects of a network. In the first place, the increase in the volume inventory decreases the unit transportation cost. In the second, in a network with a sufficient number of dismantling units, storage sites, and treatment units, the logistics can be optimized to minimize the cost of collection and transportation.

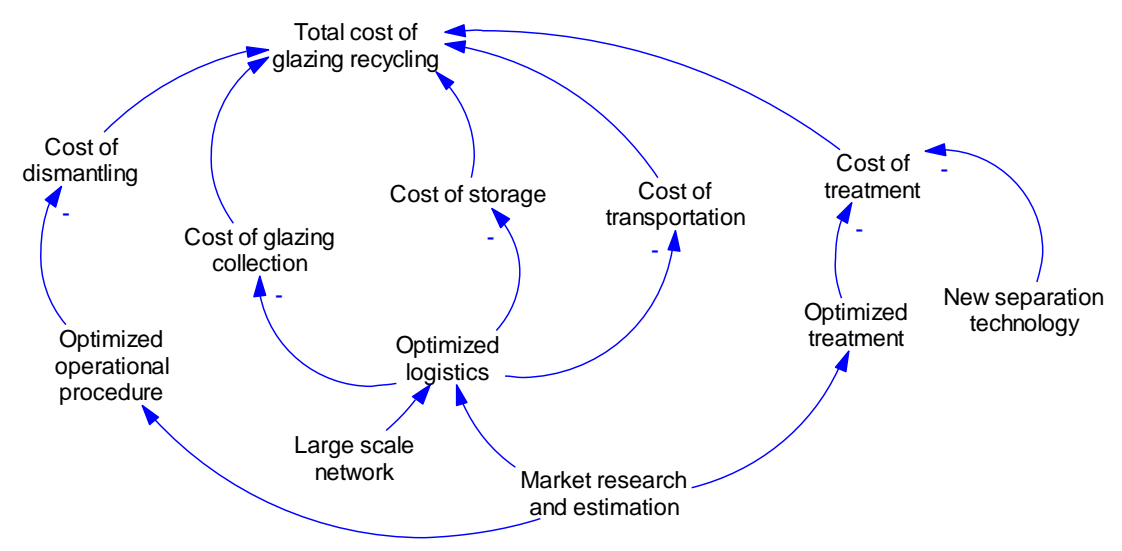

Figure 4. Dynamics of cost decreasing within the recycling network

Establishing a recycling network contributes to the reorganization and optimization of operations for each stakeholder, seeking to decrease the cost for the network as a whole. This subject has been previously explored in detail (Farel, Saitou et al. 2012) and will not be developed here. In brief, for each operation, e.g. dismantling, there are several alternatives, e.g. all glazing, only windshield, or one-sided windows. Each alternative has its cost and quality attributes, and imposes the technical restrictions. The storage and treatment of mixed glazing is not the same as that of the side windows, and produce different cullet with differing quality and cost. Nonetheless, the alternative choice can be optimized while maintaining minimal total costs for the whole network.

\subsection{Strategic and political decision}

The politico-environmental decisions can influence the dynamic of the network through several mechanisms, direct or indirect, shown in figure 5. First of all an inventory of glazing will be developed in dismantling units, while maintaining the obligation of glazing dismantling to dismantlers. Thus, a solution should be found for moving the glazing from the dismantling site, mainly because of physical space constraint. There are only two practical solutions: to take the glazing to landfill, sell or give the inventory to a recycling network.

The first choice poses significant costs for the dismantlers. The motivation therefore increases to dismantle units for with the aim of joining a national recycling network see figure 5 , arrow $d$ for further detail. Additionally, the existence of an increasing inventory of glazing can motivate the collection and transportation stakeholder to add this service to their logistic services. The motivation of the logistic stakeholder to join the network is marked with arrow I on the figure 5 .

Secondly, increasing the consequence of landfill tax, is that landfill cost is increased. As previously mentioned, this dynamic implores (via shredder pressure) the dismantler to remove the glazing from the ELV shell. Similar to the first situation, the increasing amount of inventory increases the motivation of the dismantler to join a national recycling network. 
Thirdly, by applying a penalty in case of not reaching the minimum rate of reuse and recovery, the cost of non-glazing recycling increases. The required payment of this penalty by the stakeholder is yet to be known. Car manufacturers are however largely implicated. Accordingly, they have strong motivation to be an active stakeholder to establish a recycling network (arrow c).

Fourth, increasing the tax of $\mathrm{CO} 2$ emission contributes to increasing the motivation of the glass production industry to use cullet in furnaces, and therefore to increase the demand and the price of cullet in the market (arrow g).

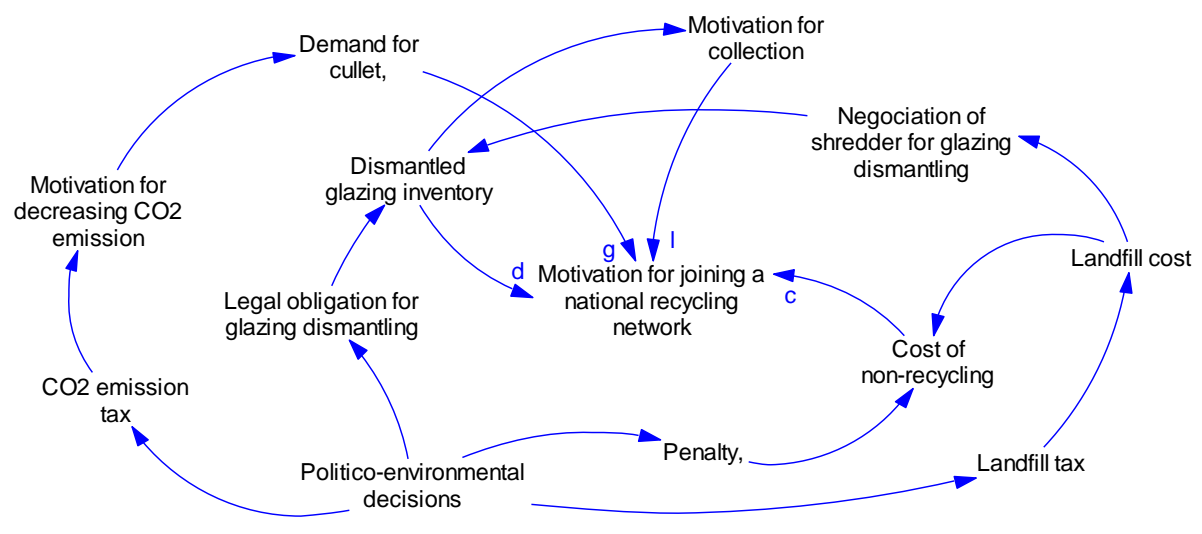

Figure 5. Dynamics of decisions and motivations influence on the recycling network

To demonstrate the effect of politico-environmental decisions on the recycling network we choose three scenarios to simulate the effect of the penalty amount on the network CBA. Three scenarios for constant small amounts, high amounts, and increasing amounts of penalty are demonstrated in section 5 .

To conclude, it is possible to simulate the cost and benefit of recycling network with modeling the changes in four variables. Cullet price and landfill cost as two exogenous variables, and logistics cost and network coverage as endogenous variable.

\section{Data collection: ELV glazing recycling in France}

According to ADEME (2008), each year in France 1.7 million ELVs are produced, of which at least 1.5 million are collected through different sources such as automobile parks, insurances, and concessionaries.

A typical European car contains four types of glazing: windshield, fixed side windows, mobile side windows, and back windows, each associated with different material concentration ranges (Figure 6). Despite the simple structure of side windows, the windshield and back windows glass is mixed with polyvinyl butyral (PVB) interlayer in laminated glass of windshield, enamel/ceramic inks, silver printing electrical connectors. There is also encapsulation materials and fixing clips in all types of windows (Saint-Gobain, 2010). On average, a car contains $41 \mathrm{~kg}$ of glass, representing $2.9 \%$ of the total car weight, and $3.2 \%$ of the dismantled ELV body, a part which is continually increasing for new cars. 


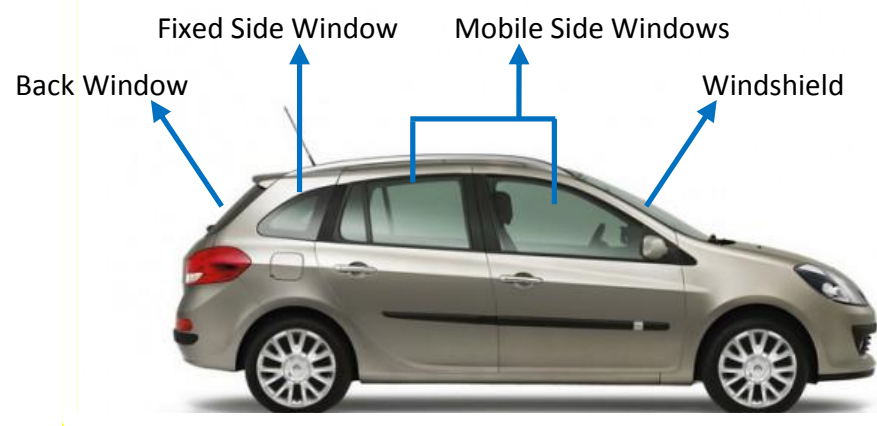

Figure 6. Glazing in a typical European car

\subsection{Dismantling}

Dismantling the glazing is a manual procedure which is relatively slow (about 6-8 minutes per ELV). The dismantled glazing must be stored in special boxes to prevent pollution, for the further collection. Glazing removal is a simple task, and does not add a high extra cost. Table 3 shows the cost balance details of the dismantling activity, and the details about adding the glazing removal.

\begin{tabular}{|l|l|l|}
\hline & Dismantling ELV & $\begin{array}{l}\text { Dismantling } \\
\text { glazing }\end{array}$ \\
\hline Procedure & Manual & Manual \\
\hline Time $(/ E L V)$ & $120 \mathrm{~m}$ & $6-8 \mathrm{~m}$ \\
\hline Activity Cost & $546 € /$ ELV & $1.25 € /$ ELV \\
\hline Other costs & - & Storage \\
\hline Revenue & $517 € /$ ELV & $* 10-20 € / \mathrm{t}$ \\
\hline $\begin{array}{l}\text { Energy } \\
\text { consumption }\end{array}$ & Not available & No extra \\
\hline CO2 emission & Not available & No extra \\
\hline
\end{tabular}

Table 3. Cost and benefits of dismantling in France, source (ADEME 2006)

* Sale price for recyclable glass, not inclusive of transport.

If glazing were to be removed from ELV, for reuse and recycling, there are two boundaries for the glass separation procedures: (a) to remove it carefully, so the minimum metal and plastic stick to glazing (b) to remove frames or other accessories such as lock systems for side windows very quickly, for which specialized tools (such as a mechanical arm) may be needed. Based on the authors' observation in an industrial dismantling site in France, on average, $80 \%$ of the total glazing (i.e. approximately $36.9 \mathrm{~kg} / \mathrm{ELV}$ ) can be dismantled in normal practice. Depending on the collection requirements, glazing after removal can be stored in separate boxes for side windows (simple glazing), windshield (laminated glass) and back windows for electrical connectors, or be mixed.

\subsection{Shredding and exposing to landfill}

After dismantling, ELV shell goes to shredding and, after metal separation the shredding residual including the glass is disposed at landfills. On average, an ELV after dismantling weighs $645.1 \mathrm{~kg}$, of which after shredding 445,3 $\mathrm{kg}$ (ferrous metal) with 102,6 $\mathrm{kg}$ process waste, $20 \mathrm{~kg}$ (non ferrous metal) and from the residual, 14,7 kg used for energetic valorization. In the remaining 97,1 kg for landfill, there are $42 \mathrm{~kg}$ of glass. The landfill cost in France is $108.4 € / T$ (ADEME 2006). If glazing were 
to be removed from the ELV shell, a considerable percent would be reduced from the landfill disposal, which would save costs in terms of landfill and transportation.

\subsection{Collection and transportation}

The existence of the ELV recycling network suggests that dismantled glazing is collected and transported to treatment units. The cost of this activity is the sum of logistics from dismantling units to redistribution centers, the storage cost, and the logistical cost of sending the glazing to the treatment centers. There is also an extra cost for the special box needed to transport the glazing. Similar to previously outlined steps, this is an existing activity for ELV components and not for glazing only.

There are two main approaches for ELV glazing collection: The first assumes separate logistics only for ELV glazing. Second, to modify the existing ELV collection and transport logistics to integrate ELV glazing with necessary considerations to prevent the pollution. The collection cost and transport cost are functions of the geographic distribution of dismantling, redistribution and treatment units, the fuel price and coverage of the network. Although it is not possible to estimate the costs for the second approach, it would appear that costs can be lowered by 20 to 50 \% (authors' communication with a professional actor of collect and transport). It would be possible to organize local glazing collection from small dismantling and repairing units, under the condition that storage of dismantled glazing does not implies extra costs, or difficulties.

\subsection{Glass treatment}

Glazing will be treated in the flat glass treatment center. This activity is comprised of the following operations: shredding, sieving, magnetic picking for ferrous metal separation, cyclone for PVB removal, Eddy current for nonferrous metal removal, and optical separation, as shown in Figure 7. ELV glazing can in fact be treated in the same production line as building laminated glass. However, in some cases initial investment is needed for a pre-crusher in order to separate the PVB film from the glass in treating windshields.

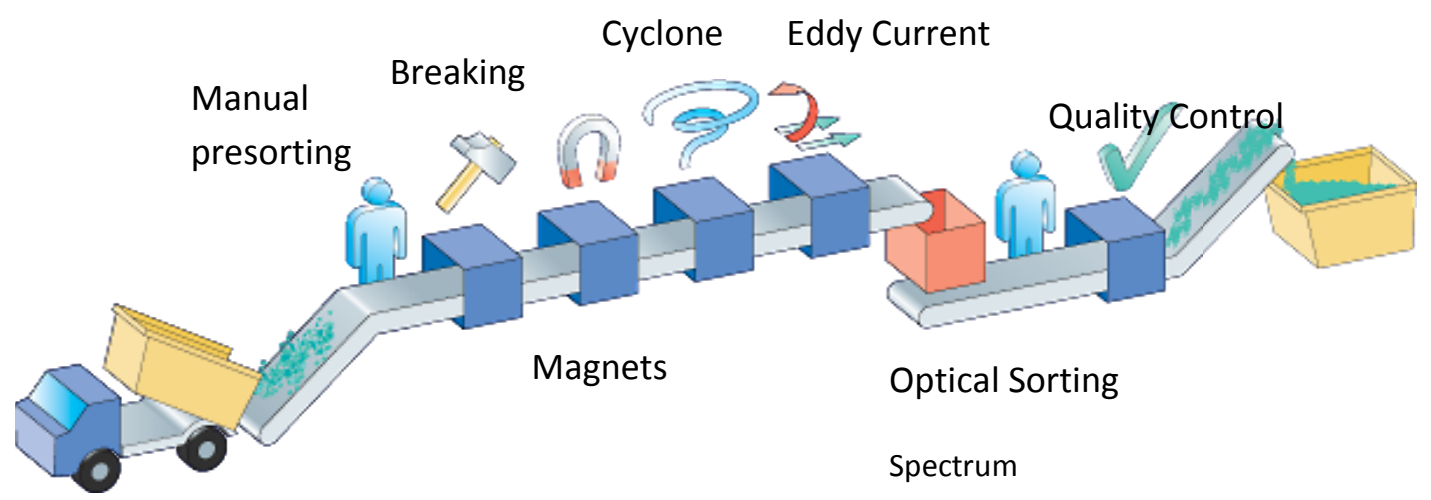

Figure 7. Process of treatment for laminated flat glass (Maltha 2011) 
In the glass treatment line, after the breaking step, the flow is separated to two lines: 0-5 mm and 5$10 \mathrm{~mm}$ cullet. In general, the production is distributed by $60 \%$ for $0-5 \mathrm{~mm}$ cullet and $40 \% 5-10 \mathrm{~mm}$ cullet, regardless of input glass. Treating ELV glazing does not necessarily imply added configuration or costs for a treatment line. For laminated glass and windshield, there is a by-product of PVB representing less that $5 \%$. The income of this activity is to resell the cullet from recycled glass. In real practice, glass recyclers could have different products, e.g. 25 types of cullet with different specifications, by mixing predefined types of cullet.

Does the ELV origin of the glazing place a limit on the quality of the produced cullet? To answer this question, we conducted an experiment in with the help of project industrial partners. A sample of dismantled ELV glazing has been sent to treatment units, with the setup for high quality cullet production, destinated for the flat glass production market. Windshield, back windows and sidewindows have been treated separately and the produced cullet has been analyzed in the laboratory. Table 4 shows a concise summary of the test result detail.

Table 4. ELV Glazing cullet analysis result

\begin{tabular}{|c|c|c|c|c|}
\cline { 2 - 5 } \multicolumn{1}{c|}{} & Cullet & By-product & Waste* & Recycling quote \\
\hline Windshield & $93.39 \%$ & PVB foil $6.013 \%$ & $0.597 \%$ & $99,403 \%$ \\
\hline Side window & $99.02 \%$ & - & $0.597 \%$ & $99.02 \%$ \\
\hline Back window & 95.02 & - & $4.979 \%$ & $95.02 \%$ \\
\hline
\end{tabular}

*Waste: aluminium parts, other non-ferrous, glass loss, pre-sorting sent to landfill

Despite the fact that the detailed results of physio-chemical analysis of the produced cullet remained confidential the high yield rate of production in the process line for flat glass production is technically feasible. Using field observation we have come to the understanding that the cullet as the final product is produced in two independent steps. First of all, the treatment process, which is optimized directly for the incoming glass feed. Then, different cullet batch (with different qualities) will be mixed to make the final product, based to the customer order, or predefined product. Thus, considering the modest share of ELV glazing, there is little quality problems for cullet production. Nonetheless, the use of cullet is not limited to flat glass production, and can be extended, as explained in the next section.

\subsection{Summary}

In the light of details that have emerged from this evaluation, it is possible to ask the following question: Why does ELV glazing not yet exist? To answer question one should look at the business model of dismantling. In the absence of a glazing recycling network, there is no particular demand for dismantled glazing, so the collector is not interested in buying glazing and reselling it. Moreover, the collection and transportation costs are higher than the price of produced cullet. Thus ordering the collection is of little economic interest to the glass treatment stakeholder even if offered it free of charge by the dismantler.

Is motivation strong enough? As the table shows, a recycling network brings economic profit for almost all stakeholders. Furthermore there is another important stakeholder for this network, the automobile manufacturer, who is not present in the present model. The latter could have strong motivation for a recycling network, in both environmental and economic terms. In fact, the EU 
directive on ELV brings the reuse and recycling obligations of $95 \%$ to the car manufacturer, and the potential penalty in case of failure is addressed to this stakeholder. There is thus fairly strong incentive for the car manufacturer to contribute to the creation of such a network.

This section cast a detailed lens on the individual stakeholders and evaluated the economic performance of each step of an ELV glazing recycling network. It is possible now to go further and investigate the economic performance of the network as a whole, and try to assess the performance in current and under future situations.

\section{Simulation result for the main variables}

The economic balance of the future ELV glazing recycling network in France depends on the values of the time-sensitive variables of the cost-benefit model. In this section we lay the focus on the previously identified four time-varying key variables, and describe their evolution dynamics.

In order to estimate the value of those key variables over a relatively long time scale, the evolution function needs highlighting. Then, we simulate the CBA of the recycling network based on each evolution dynamic of all key variables (other values remains unchanged) on a 50-year time scale.

In order to compare and evaluate future evolution of different possible scenarios for the ELV glazing recycling network, we use the SRI matrix, a tool developed at the Stanford Research Institute in the late 1970s. The SRI matrix considers four general trends: expected future, worst case, best case, and a radically different alternative, i.e. a scenario including surprising or unusual events (Bishop, Hines et al. 2007).

Table 5. Growth or decay dinamic of key variables

\begin{tabular}{|l|c|c|c|}
\hline $\begin{array}{r}\text { Growth/decay } \\
\text { Dynamic }\end{array}$ & $\begin{array}{c}\text { Linear } \\
\text { change }\end{array}$ & $\begin{array}{c}\text { Non linear } \\
\text { change }\end{array}$ & No change \\
\hline Cullet price & D 1.1 & D 1.2 & D 1.3 \\
\hline Landfill cost & D 2.1 & D 2.2 & D 2.3 \\
\hline
\end{tabular}

The base case is defined as a scenario in which all variables take the present value and remain unchanged. The total cost of not recycling and recycling in this situation are respectively 4.9 million euro and 5.05 million euro per year.

This section presents the results of simulation based on the previously presented model and collected data, using the system dynamics simulator Vensim. For each scenario simulation, there is an estimated value range for the concerned variable of the scenario on the time scale, and all other values remain unchanged. The behavior of the system is shown in graphic schemes and explained in greater detail.

\subsection{Cullet price evolution}


The price of cullet has manifested an increase lasting recent decades, as shown in Figure 8 (a) extracted from Eurostat (2011). The result of data extrapolation for cullet price with three dynamics of D1.1, D1.2 and D1.3 are presented in the Figure 8 (a). The result of cullet price increase in relation to those three dynamics is shown in Figure 8 (b), compared with the base case for the balance of no ELV glazing recycling.

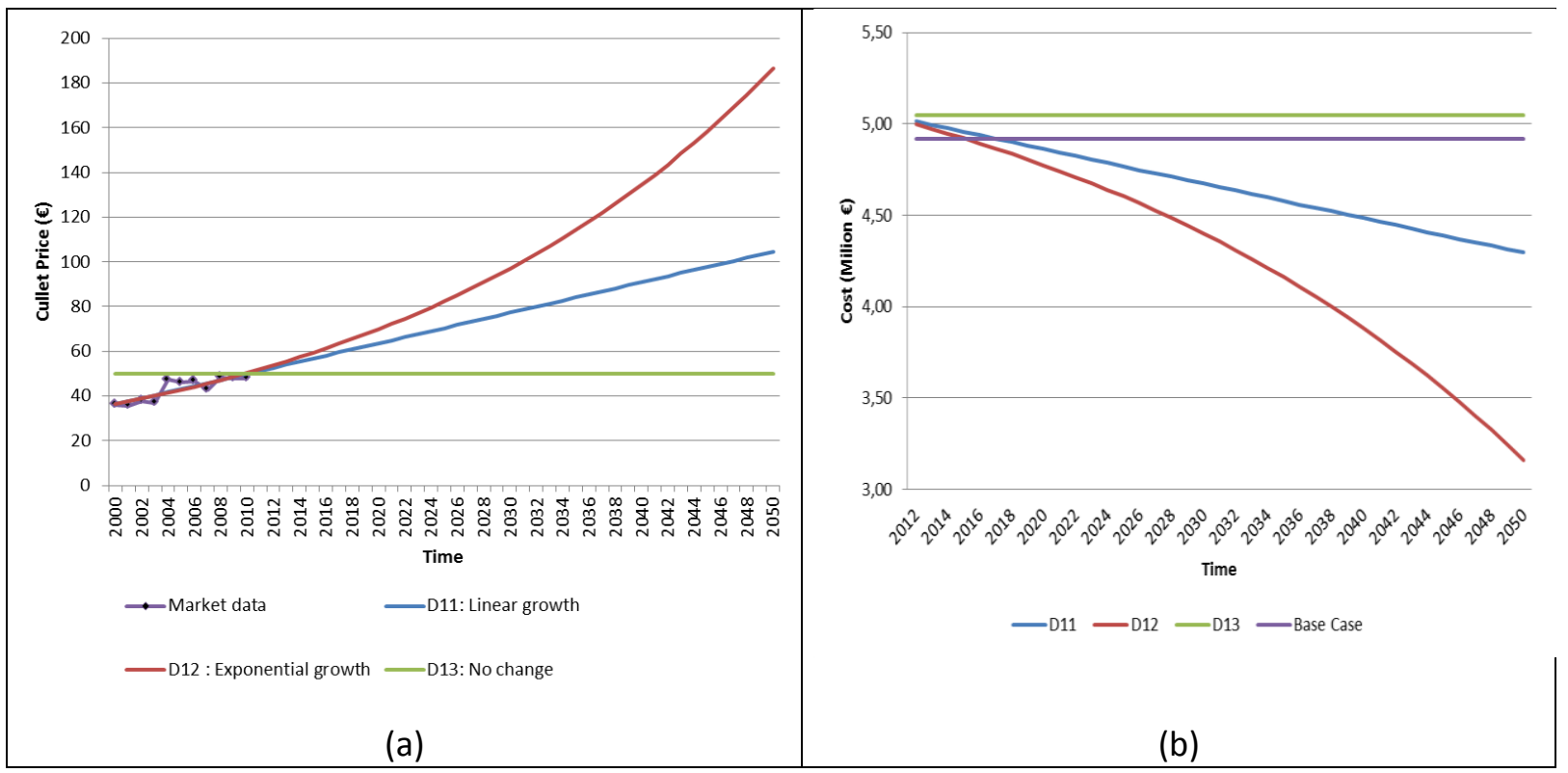

Figure 8. Estimation of cullet price evolution (a) and its effect on recycling balance (b) in three dynamics.

As the Figure 8 shows, no change in cullet price (D1.3) is the worst situation for the network. This is due to recycling costs. If the cullet price continues to increase with a linear growth (D1.1), its balance curve crosses the base case curve at 2017 , so recycling becomes less costly.

\subsection{Landfill Cost Evolution}

The landfill cost in France shows an increase rate (Sydeme 2009). With environmental decisions such as an increase in landfill tax (Fischer, Lehner et al. 2012), this cost would be increased in the future. Figure 9 (a) shows data extracted from (Sydeme 2009) and two extrapolations for future values: linear growth (D21) and exponential growth (D22). D 23 presents no change in cost of landfill. Since the landfill cost evolution influences the cost of no recycling (base case), these three growth estimations are presented separately in Figure 9 (b) to (d).

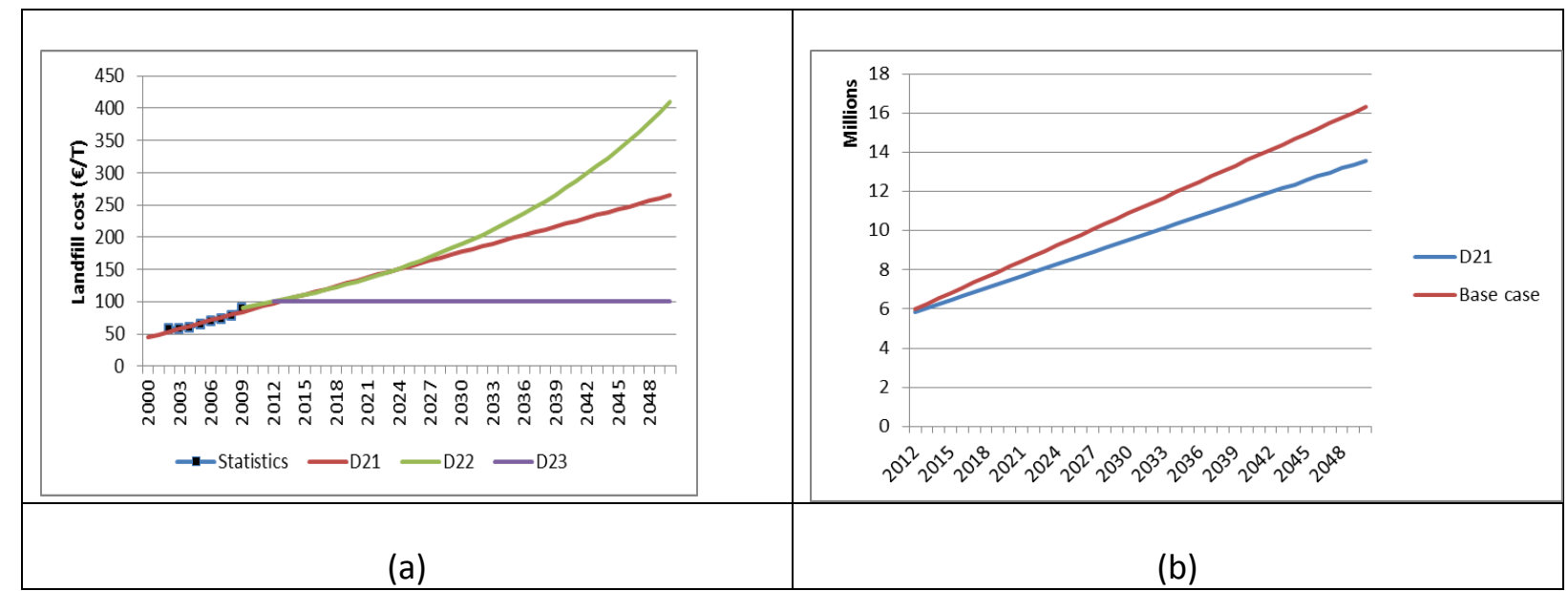




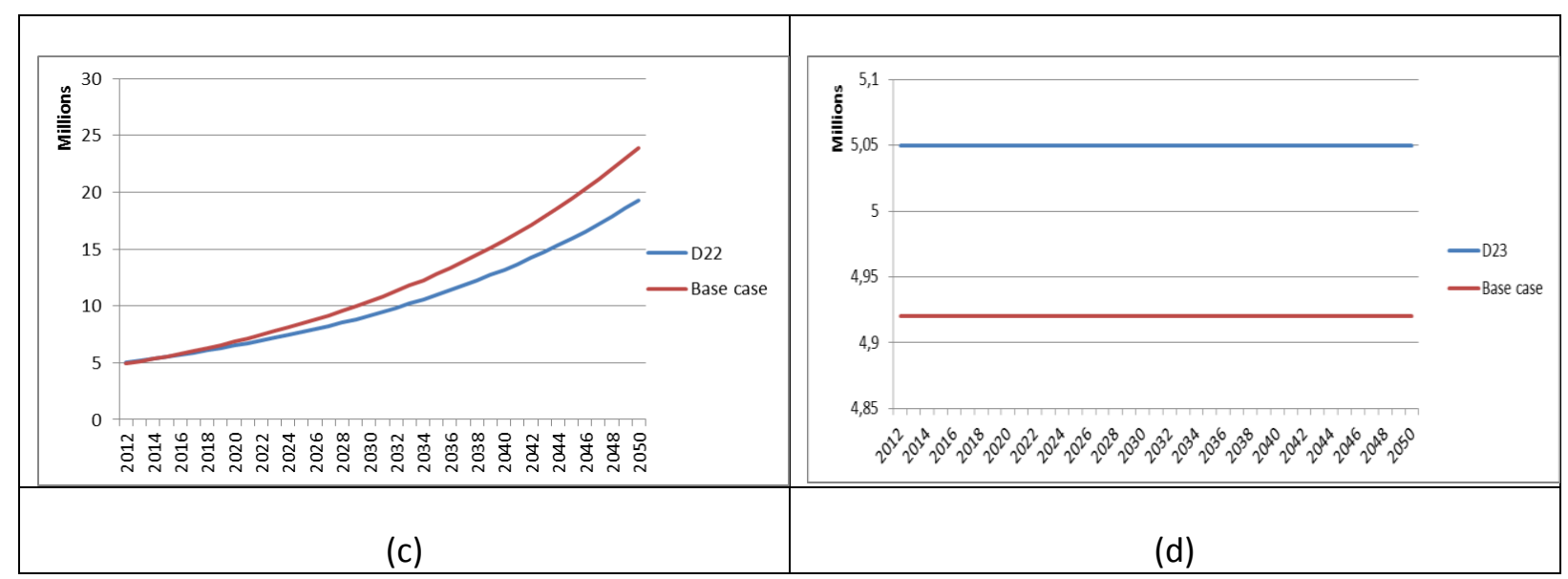

Figure 9. Estimation of landfill cost evolution (a) and its effect on recycling cost balance in three dynamics (b), (c) and (d)

The figures above reveal that the case of no landfill cost increase is the best situation for the recycling balance (D23). The linear growth (D21) is the average situation, versus the exponential growth, which makes the situation the worst of the three for the recycling network. Despite the negative contribution of landfill cost, the increase in the recycling network's economic situation, it can be of interest to more dismantlers and shredders in terms of joining the network coverage.

\subsection{Logistic cost and network coverage evolution}

In order to estimate the value of these two endogenous variables the following hypotheses are considered.

First, the total collection and transportation cost is estimated $80 € / T$ for the current situation and 20 $€ / T$ for the optimized network logistics in France (ISEL 2011). Considering these two dynamic respectively as the expected case (D31) and the best case (D32), it is possible to imagine a worst case (D33) with an increase in collection and transportation costs. In Figure 10 (a), the three dynamics for the logistic cost evolution in future are presented over the time period of 10 years. Second, the network coverage can reach from zero to total coverage by three dynamics: a linear growth (D41), a power growth (D42) or a logarithmic growth (D43). In Figure 10 (b), the three dynamics for the network coverage evolution in future are presented over the time period of 5 years.

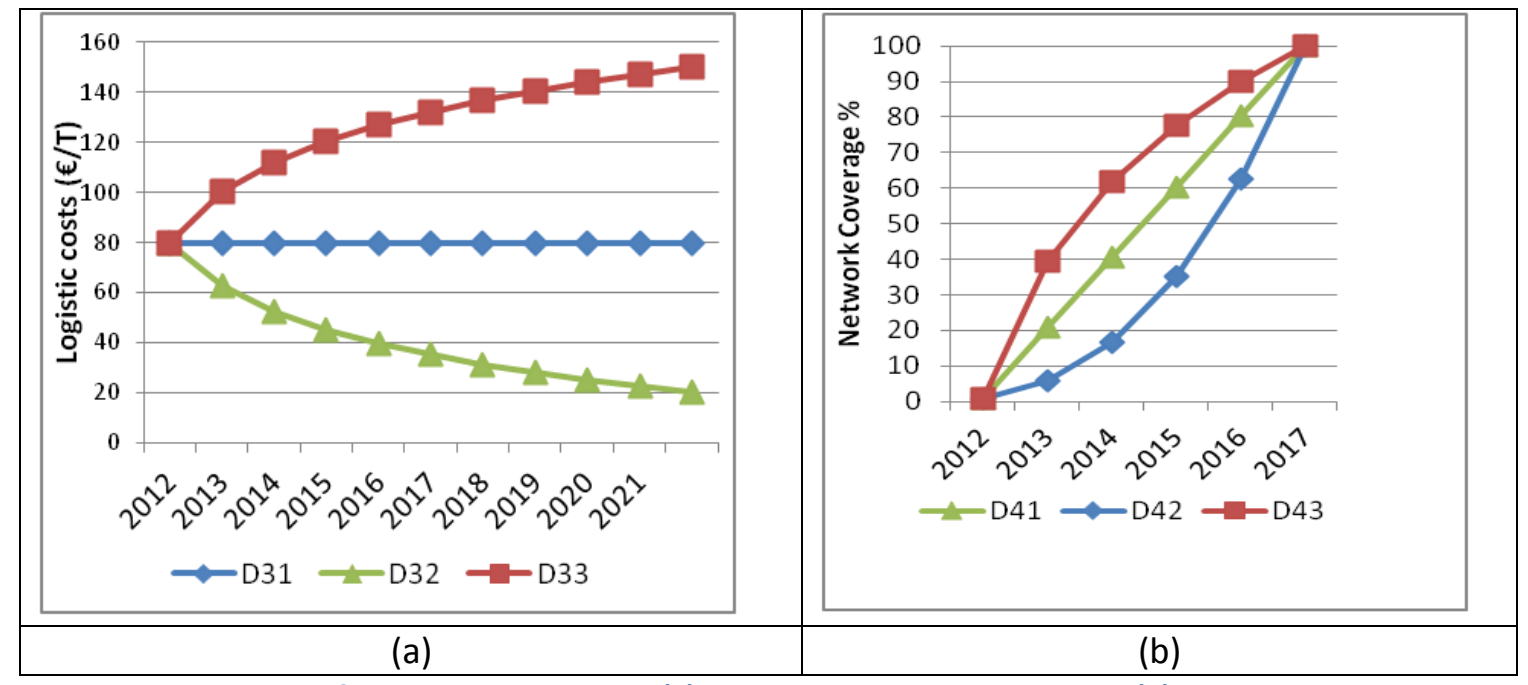

Figure 10. Estimation of Logistics cost evolution (a) and Network coverage evolution (b) in three dynamics 


\section{Future scenarios for the recycling network}

The key time-varying variables of the model and their estimated value using a system dynamics simulator, has the advantage of running the simulation under mutli-situation. We use a crossing SRI for external and internal variables of the recycling network.

Two external variables, the cullet price and the landfill cost together provide three situations for the recycling network: the best case, the expected case, and the worst case (see Figure 11, left). Along similar lines, two internal variables; the logistic cost and the network coverage, can be managed within the following three situations: best case, expected case, and worst case (Figure 11, top-right) based on their dynamics. The crossing of external and internal variables provide nine scenarios for ELV glazing recycling. With the help of a developed system dynamics model in Vensim, the CBA of the recycling network in each sceanrio is simulated, and presented as follows.

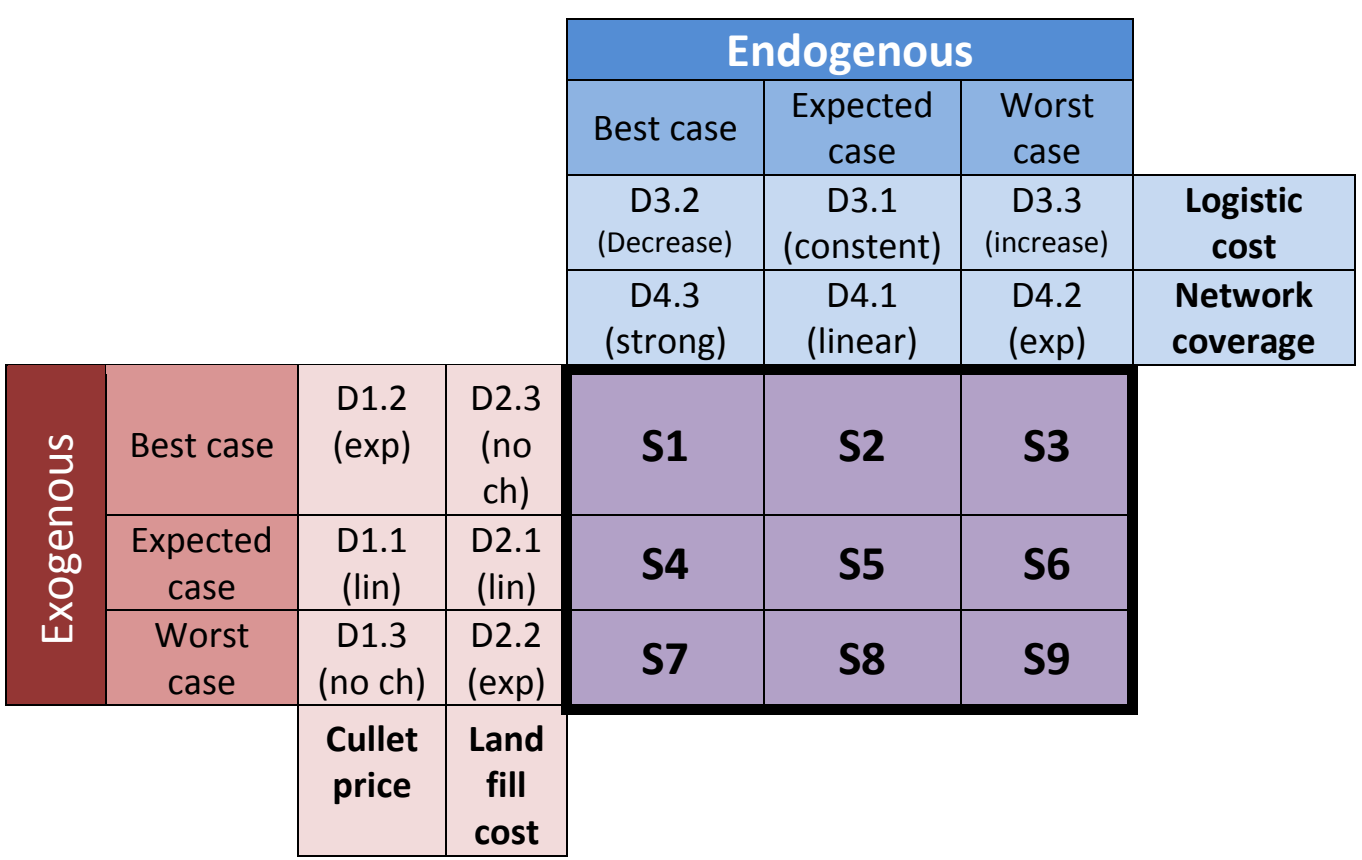

Figure 11. Nine scenarios for the ELV glazing recycling network

\subsection{Simulation result: CBA of glazing recycling}

Figure 12 shows the CBA of ELV glazing recycling in France for each scenario in a 50-year horizon. From a general perspective and based on exogenous change, three catergories can be distinguished: The first catergory corresponds to the best case for exogenous variables. It includes scenarios 1,2 and 3. The second category corresponds to the expected case for exogenous variables and includes senario 4,5 and 6 . The third category corresponds to the worst case for exogenous variables and includes scenario 7,8 and 9 .

In the first category, the CBA curve of all scenarios crosses the horizontal axis. There is an observable change in value from cost to profit. Scenario 1 is the best possible scenario, in which the network revenue is at its greatest and the time it takes to reach zero line is at its least. In this category the external variables, the revenue from the cullet sale and cost saving from the landfill are experiencing in the most favourable conditions for the network. The scenarios internal varaibles are differentiated in the time to reach the beack even point. 
In the second category, where the exogenous variable have an expected trend, the trend of endogenous variable significantly changes the economic balance of the recycling value chain. The curve of scenario 4 where the exogenous variables are at their best trend (maximum network coverage and minimum transportation costs) shows that the horizontal axis (break even point) is reachable but in the long time horizon (more than 100 years). Alternatively, scenarios 5 and 6 never converge to the horizontal axis. These scenarios however show a stable balance for the value chain.

In the third category, where the exogenous variables have the worst case trend, all three economic balance curves of scenarios of 7, 8 and 9 show a decreasing balance (cost increase) for the recycling value chain. Scenario 9 is the more expensive scenario where the endogenous variables are at their worst trend too. The difference between endogenous variables trend which is the result of stakeholders' decision and organisazation can decrese the slope of the balance curve. As a result this leads to a smaller recycling balance, as in scenario 7 .

In summary, the simulation on estimated trends of exogenous and endogenous variables of the recycling value chain system shows the following results:

a) Exogenous variables trends role in economic performance of the recycling value chain is more significant than endogenous variables.

b) When the exogenous variables are at the expected case trends, above called category two, the endogenous variables trends is critical to turn the economic performance to either a profitable scheme, or costly scheme. 


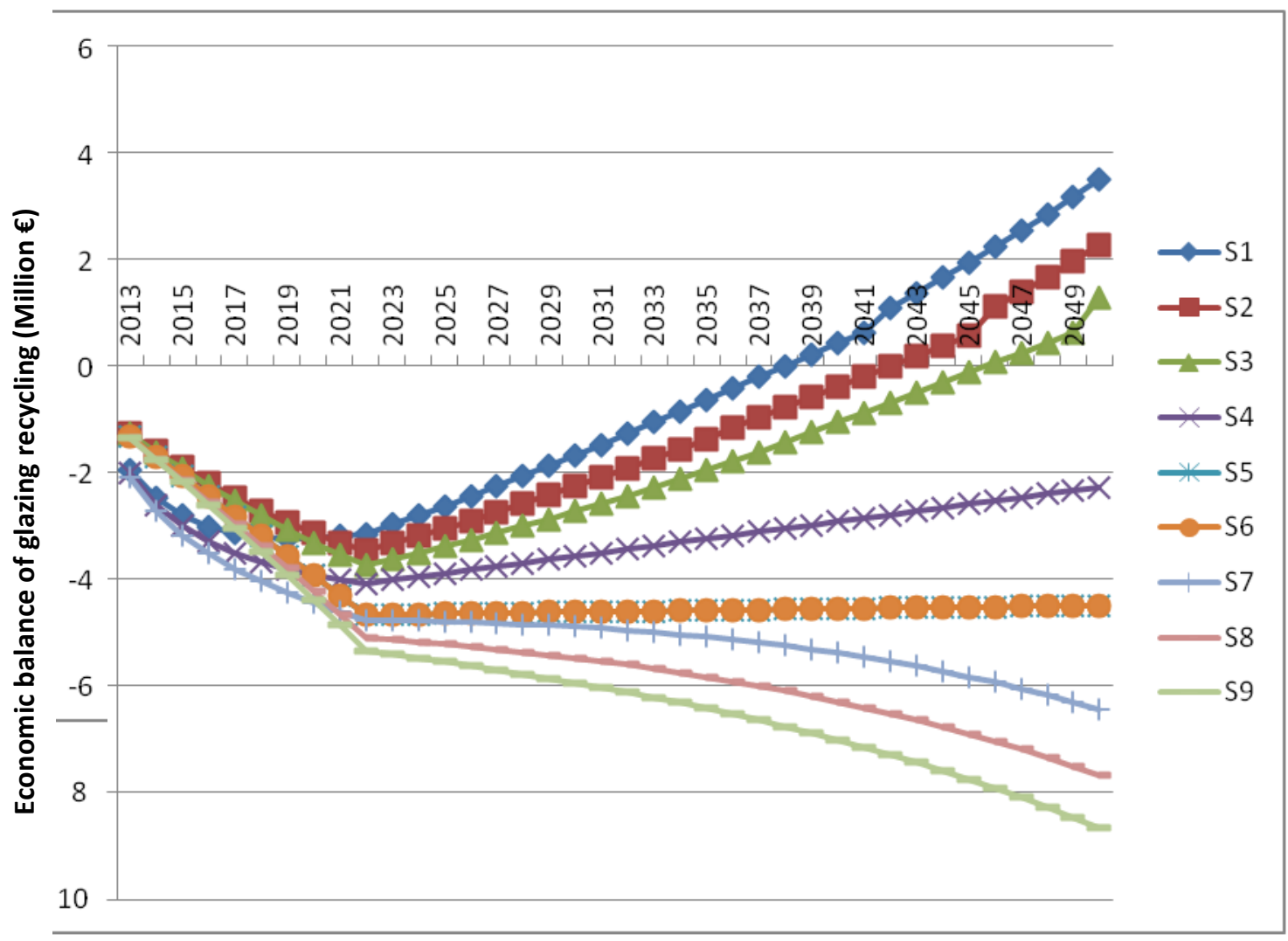

Figure 12. Economic balance (income - costs) of glazing recycling in 9 scenarios

Figure 13 brings the focus to the early years of the network establishment. As the diagram above depicts an initial difference between the groups of scenario 1, 4, 7, and the other scenarios. The commonality that these three scenarios share is the best circumstances in terms of internal variables. In these scenarios the amount of cost increases from 2013 to 2022. This is significantly less than other scenarios and the cost decrease starts on a steeper slope than the others. The reason for the gap in the glazing recycling network within this group is that the rate of network coverage is greater than other scenarios. Thus the greater the amount of dismantled glazing the greater the costs to the network, particularly in terms of transportation and treatment.

In the second group, scenarios 2 and 3 show less of a cost increase than others, and take on a decrease rate similar to that of scenario 1 . The reason is these two external-variable scenarios are at their best. Finally, scenarios 8 and 9 have the greatest cost increase and after the peak in the year 2022 continues to increase on a narrower slope. 


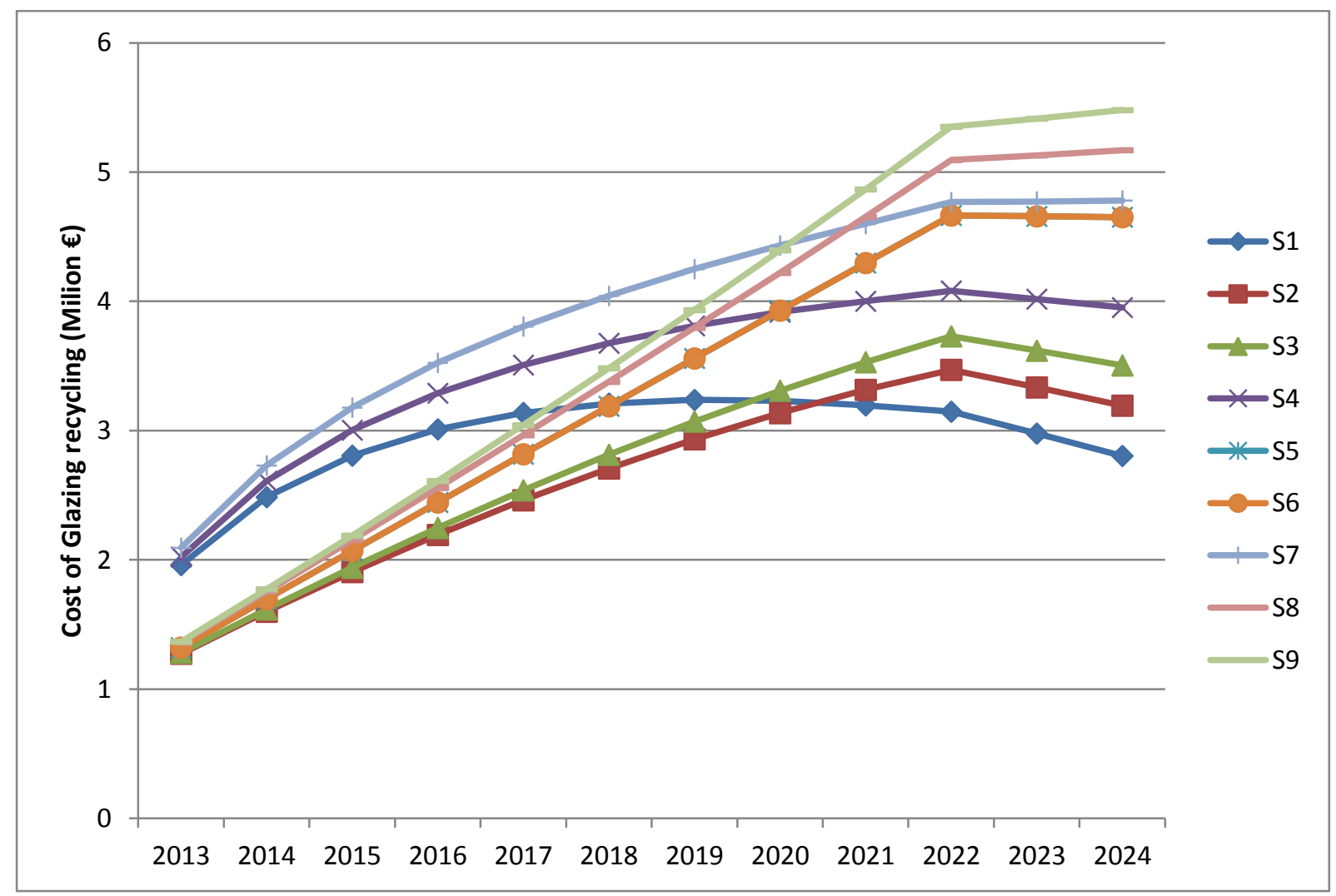

Figure 13. Cost of glazing recycling in 9 scenarios, focus on the beginning years

\subsection{Gain of glazing recycling (cost savings)}

To complete the glazing recycling CBA, the total economic balance of recycling aside, it is also important to investigate the gain of the network establishment. This refers to the difference in balance between the recycling and the non-recycling of ELV glazing. In other words, it is important to know whether or not the glazing recycling saves costs.

Figure 14 shows the simulation of glazing network economic gain along a 50-year horizon. From a general standpoint, all scenarios have positive gain which increase. Unexpectedly, the order of scenario groups in economic gain is the turned around in terms of the order in network total costs. The group of scenarios 7,8 et 9 have the largest economic gain. In these scenarios the external variables are at their worst, including significant landfill cost increase. Thus, the establishment of glazing recycling poses significant savings in terms of costs. Accordingly, scenario 7 has the greatest gain as it depicts the worst case situation when it comes to landfill cost, which is on an exponential increase along with the best case for internal variables: exponential decrease in transportation costs and logarithmic increase of the network coverage.

Scenario 1 shows one of the least economic gains, although it had the best case scenario for the least cost and the shortest break point reach (Figure 14). The reason is in scenario 1 conditions, best case for endogenous and exogenous variables trend, the economic blance of non-recycling is not too negative. 


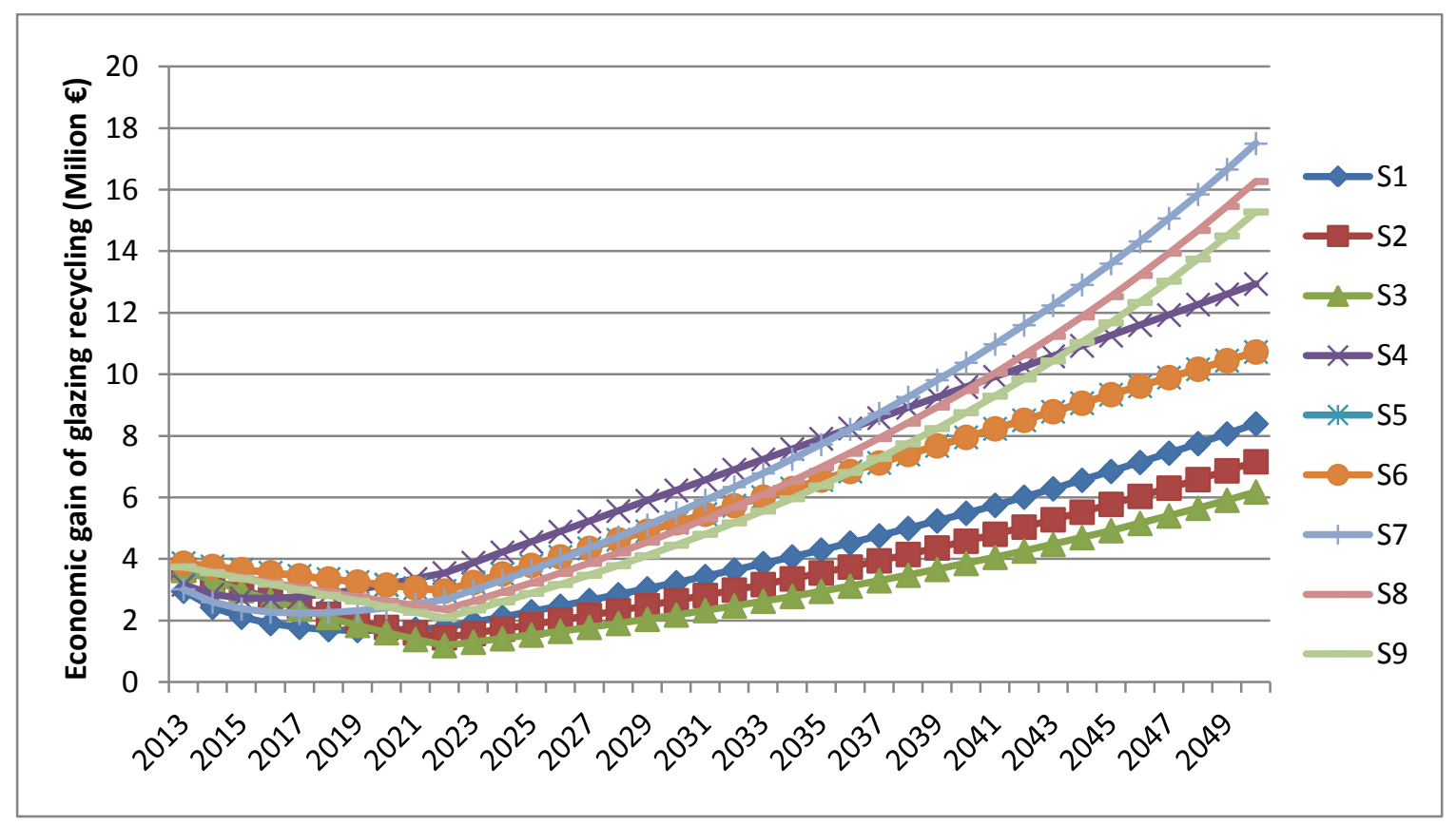

Figure 14. Gain of glazing recycling (difference between recycling and non-recycling economic balance) in 9 scenarios

\section{Conclusions and perspectives}

By the time the declaration of the new ELV directive for glazing reuse and recycling, in 2015, stakeholders of the ELV recycling network should reconsider the current scenario of not recycling. In several recent communications ELV glazing recycling has been considered as a non-profitable network, with some technical difficulties. Rough propositions have been made to provide financial support, such as public subsidy, for dismantling and sending the glazing for the substitution market (Gillot 2000; GHK 2006; ADEME 2008). In this paper a framework for performance evaluation has been proposed and the cost and benefit of a future ELV glazing recycling has been demonstrated, modeled, and evaluated. Technical and economic details of activities have been discussed and the main barriers and potential solutions have been extracted from field observation and interviews and active survey.

The result of the simulation in nine future scenarios shows the strategic importance of establishing a national ELV glazing network. The gain of this network is positive, and would increase after the achievement of full network coverage. In certain scenarios the recycling network would become financially beneficial, and could be self-financed.

The environmental impact of ELV glazing network is of little importance compared to technoeconomic performance. In this paper however, the environmental evaluation has been limited to first analysis and primary indicators (Table 1 ), due to the particularly complex nature of a life cycle analysis within a network. This is also a result of the considerable lack of data. Altogether, the environmental evaluation of ELV glazing network within different operation scenarios and against the future evolution requires a separate study.

It is important to note that ELVs contain a considerable number of valuable parts and materials for which the reuse and recycling follows a general recycling network. Thus, the performance of a 
recycling network on material clearly depends not only on the specific activities of collect-recyclereuse, but also on the performance of the general network. The added value varies greatly between materials, and a negative value of an activity for a given material might be compromised with other materials or activities.

One main problem in doing research on recycling value chain is that there are various activities, implemented by various independent stake holders with differing business logics. The required data for modeling, performance evaluation and simulation are of significant difficulty to access, and suffer from reliability issues. This paper is thus a first attempt to put together models and data from different sources to investigate the ELV glazing performances, and create and parameterize multiple future scenarios, in order to provide the decision maker a considerable amount of information about the network dynamics.

In order for a future ELV glazing recycling network to be established in France, it is necessary to favor the potential stakeholders with clear vision and supportive methods and tools, to aid the decision process towards joining the network. Not only do all stakeholders prefer a voluminous flow, but also the total value of the network could be mutually augmented. The true value of a recycling network is the contribution to the environment, by creating and encouraging economic motivation.

Last but not least, the usage of System Dynamics in this study gave the possibility to demonstrate system variables with different detail levels, provided easily understandable graphical schemes of relationship between variables, and finally was a principal step toward building a quantitative model and associate the simple relation with mathematical equations. Moreover, in an industrial context study where the communication with industrial stake holders is crucial such as the present paper, the System Dynamics and the associated tools shown to be adequate mean for discussion and formalization with operational and industrial partners.

How then should the network be started? This brings forward the governance of a value chain from the analysis and estimation on paper to the real challenge of collaboration, role-play, and strategic alliance between stakeholders. The organization of a network, its financial management, where and how to invest as well as when and how to redistribute the profit are issues requiring further study. 


\section{References}

ADEME (2006). Campagne de démontage et de broyage de 304 VHU et étude des flux de matériaux issus du traitement.

ADEME (2007). "Véhicules hors d'usage (VHU) / Rapport annuel de l'Observatoire."

ADEME (2008). Etat des lieux de la valorisation des materiaux issus du traitement des vehicules hors d'usage.

Bellmann, K. and A. Khare (2000). "Economic issues in recycling end-of-life vehicles." Technovation 20(12): 677-690.

Bishop, P., A. Hines, et al. (2007). The current state of scenario development: an overview of techniques. Houston, Texa, University of Houston.

Boardman, A. E., D. H. Greenberg, et al. (2001). Cost-benefit analysis: concepts and practice. New Jersey Prentice Hall.

Butler, J. and P. Hooper (2005). "Dilemmas in optimising the environmental benefit from recycling: A case study of glass container waste management in the UK." Resources, Conservation and Recycling 45(4): 331-355.

Campbell, H. F. and R. P. C. Brown (2005). "A multiple account framework for cost-benefit analysis." Evaluation and Program Planning 28(1): 23-32.

Duran, X., H. Lenihan, et al. (2006). "A model for assessing the economic viability of construction and demolition waste recycling - the case of Ireland." Resources, Conservation and Recycling 46(3): $302-$ 320 .

Duval, D. and H. L. MacLean (2007). "The role of product information in automotive plastics recycling: a financial and life cycle assessment." Journal of Cleaner Production 15(11â€"12): 1158-1168.

EU-Directive (2000). "DIRECTIVE 2000/53/EC OF THE EUROPEAN PARLIAMENT AND OF THE COUNCIL." Official Journal of the European Communities.

EuroStat (2011). Price developments and volume trade of glass waste EU-27.

Farel, R., K. Saitou, et al. (2012). A network flow optimization model for automotive glazing recycling. ASME IDTCE. Chicago, IL, ASME.

Fischer, C., M. Lehner, et al. (2012) Overview of the use of landfill taxes in Europe. ETC/SCP

Gerrard, J. and M. Kandlikar (2007). "Is European end-of-life vehicle legislation living up to expectations? Assessing the impact of the ELV Directive on 'green' innovation and vehicle recovery." Journal of Cleaner Production 15(1): 17-27.

GHK (2006) A study to examine the benefits of the End of Life Vehicles Directive and the costs and benefits of a revision of the 2015 targets for recycling, re-use and recovery under the ELV Directive. DG Environment

Gillot, C. (2000). "Recyclage du verre automobile." Revue Verre 6(4). 
Glass (2009). Recycling end-of-life vehicle glazing, Glass for Europe.

ISEL (2011). Logistic optimization for ELV glazing recycling network in France, ValVar Project.

Joe, P. (2008). "Representations of environmental concerns in cost, Äibenefit analyses of solid waste recycling." Resources, Conservation and Recycling 53(1,äi2): 79-85.

Kotchen, M. J. (2011). Cost-Benefit Analysis. Encyclopedia of Climate and Weather. S. Schneider and M. Mastrandrea, Oxford University Press.

Kourti, I. and C. R. Cheeseman (2010). "Properties and microstructure of lightweight aggregate produced from lignite coal fly ash and recycled glass." Resources, Conservation and Recycling 54(11): 769-775.

Leu, H.-G. and S. H. Lin (1998). "Cost-benefit analysis of resource material recycling." Resources, Conservation and Recycling 23(3): 183-192.

Malcolm Richard, G., M. Mario, et al. (2011). "Optimization of the recovery of plastics for recycling by density media separation cyclones." Resources, Conservation and Recycling 55(4): 472-482.

Maltha (2011). Corporate brochure.

NACEGroup (2009). Glass production statistics - NACE Rev. 1.1, European Commission.

Pearce, D., G. Atkinson, et al. (2006) Cost-Benefit Analysis and the Environment: Recent Developments.

Pieters, R. G. M. and T. M. M. Verhallen (1986). "Participation in source separation projects: Design characteristics and perceived costs and benefits." Resources and Conservation 12(2): 95-111.

Reindl, J. (2003). Reuse/recycling of glass cullet for non-container uses. Madison, WI, Department of Public Works.

Remade-Scotland (2003). Glass Recycling Handbook, Assessment of Available Technologies. Glasgow.

Robert, B. (1990). "Glass recycling by source separation from municipal wastes." Resources, Conservation and Recycling 4(1,Äì2): 63-75.

Sardeshpande, V., U. N. Gaitonde, et al. (2007). "Model based energy benchmarking for glass furnace." Energy Conversion and Management 48(10): 2718-2738.

Shi, C. and K. Zheng (2007). "A review on the use of waste glasses in the production of cement and concrete." Resources, Conservation and Recycling 52(2): 234-247.

Sterman, J. D. (2000). Business Dynamics: Systems Thinking and Modeling for a Complex World, Irwin/McGraw-Hill.

Suzuki, H., K. Sato, et al. (2001). "Research on dismantling technologies for improving ELV recycling." JSAE Review 22(2): 201-203. 
Sydeme (2009). "Separate and valorize, Original title "Trions, valorisons"." Journal of Sydeme information on valorization and treatment of waste, Original title: "Le journal d'information du sydeme sur la valorisation et le traitement des dechets".

Yuan, H. P., L. Y. Shen, et al. (2011). "A model for cost-benefit analysis of construction and demolition waste management throughout the waste chain." Resources, Conservation and Recycling 55(6): 604612.

Zhao, Q. and M. Chen (2011). "A comparison of ELV recycling system in China and Japan and China's strategies." Resources, Conservation and Recycling 57(0): 15-21.

Zhao, W., H. Ren, et al. (2011). "A system dynamics model for evaluating the alternative of type in construction and demolition waste recycling center - The case of Chongqing, China." Resources, Conservation and Recycling 55(11): 933-944. 